University of Nebraska - Lincoln

DigitalCommons@University of Nebraska - Lincoln

Agronomy \& Horticulture -- Faculty Publications

Agronomy and Horticulture Department

2005

Leaf Radiative Properties and the Leaf Energy Budget

Timothy J. Arkebauer

University of Nebraska-Lincoln, tarkebauer1@unl.edu

Follow this and additional works at: https://digitalcommons.unl.edu/agronomyfacpub

Arkebauer, Timothy J., "Leaf Radiative Properties and the Leaf Energy Budget" (2005). Agronomy \& Horticulture -- Faculty Publications. 693.

https://digitalcommons.unl.edu/agronomyfacpub/693

This Article is brought to you for free and open access by the Agronomy and Horticulture Department at DigitalCommons@University of Nebraska - Lincoln. It has been accepted for inclusion in Agronomy \& Horticulture -Faculty Publications by an authorized administrator of DigitalCommons@University of Nebraska - Lincoln. 


\title{
Leaf Radiative Properties and the Leaf Energy Budget
}

\author{
T.J. ARKEBAUER \\ University of Nebraska \\ Lincoln, Nebraska
}

Leaf radiative properties are the physical properties of leaves that characterize radiant energy exchange with their surroundings. Radiant energy exchange is an important consideration in studies of plant function since, for example, absorption of photosynthetically active radiation (PAR) leads to the transformation of this energy into chemical energy via photosynthesis. Thus, plant productivity, and hence, agricultural production, ultimately depend on leaf radiative properties.

Leaf temperature is an additional, very important, parameter in intimate association with leaf radiant energy exchange. This association occurs since energy gained via radiation must be in balance with energy lost through various processes and energy loss from the leaf is predicated on leaf temperature. Leaf temperature is a critical factor determining leaf transpiration (hence, crop water use), reaction rates of biochemical processes (hence, photosynthetic rates, respiration rates, growth rates and productivity), and many other aspects of plant function. Thus, leaf radiative properties not only affect leaf radiant energy exchange but are implicit in determining rates of plant $\mathrm{C}$ uptake and water loss.

This chapter will begin with an overview of leaf radiative properties. Next will follow a description of the significance of leaf radiative properties in determining the leaf energy budget. Leaf temperature will be discussed as the key component in characterizing energy interactions with leaves and their environments and a practical technique for determining the leaf temperature from the leaf energy budget will be presented. Finally, the importance of leaf conductances in the solution of the leaf energy budget will be stressed. Although much of the research cited will be focused on species of agronomic importance the general discussion is appropriate for foliage elements of any plant species.

\section{LEAF OPTICAL PROPERTIES}

In general, the radiant energy incident on a leaf surface is scattered either towards the leaf interior or away from the leaf surface. The radiation entering the leaf is scattered furthermore and eventually is either absorbed by various leaf constituents or scattered back out of the leaf. The radiation scattered out the inci-

Copyright (C2005. American Society of Agronomy, Crop Science Society of America, Soil Science Society of America, 677 S. Segoe Rd., Madison, WI 53711, USA. Micrometeorology in Agricultural Systems, Agronomy Monograph no. 47. 
dent surface (together with the energy scattered away initially) is reflected. Radiation exiting the surface opposite the incident surface is transmitted. Thus, all radiant energy incident on a leaf surface is either reflected, absorbed, or transmitted. The partitioning of incident radiant energy into these three components is determined by leaf optical properties that are manifestations of the physical properties of the leaf (e.g., its structure and composition).

Radiant energy exchange is mediated by photons traveling at the speed of light. Photons are discrete bundles of energy (i.e., they are quantized) that also exhibit wave-like properties; the energy $(E)$ and wavelength $\left(\lambda_{\mathrm{e}}\right)$ are related through the equation $E=h c / \lambda_{\mathrm{e}}$, where $h$ is Planck's constant $\left(6.6 \times 10^{-34} \mathrm{~J} \mathrm{~s}\right)$ and $c$ is the speed of light $\left(3.0 \times 10^{8} \mathrm{~m} \mathrm{~s}^{-1}\right)$. Thus, radiant interactions typically occur with characteristic spectral signatures defined by the specific energy levels that give rise to changes in the discrete energetic states of the absorbing species. In other words, a molecule will only absorb photons having specific energy levels (corresponding to specific wavelengths) - these levels are such that discrete changes in the energy states of the absorbing species occur.

The fate of radiant energy incident upon a leaf also depends upon properties associated with the source of radiation, that is, its spectral characteristics and its angular distribution. Moreover, the radiant energy incident upon a leaf surface is not reflected or transmitted equally in all directions; leaves exhibit non-Lambertian characteristics. Thus, for illumination with a narrow range of incident angles, there will be a distribution of reflectances that depend upon the view direction. The bi-directional reflectance distribution function characterizes the reflectance properties for narrow illumination and view angles. The bidirectional reflectance properties of maize (Zea mays L.) and soybean [Glycine max (L.) Merr.] leaves were appreciated by, among others, Woolley (1971) and Breece and Holmes (1971). Walter-Shea et al. (1989, 1991) also have measured the directional properties of reflectance and transmittance for maize and soybean. Further general discussion of the directionality of leaf reflectance and transmittance properties can be found in Walter-Shea and Biehl (1990) and Campbell and Norman (1998).

For many practical applications it has proven useful to divide the terrestrial electromagnetic spectrum into rather broad wavebands, i.e., ultraviolet ( 0.1 to 0.4 $\mu \mathrm{m}$ wavelength), visible $(0.4$ to $0.7 \mu \mathrm{m})$, near infrared $(0.7$ to $3.0 \mu \mathrm{m})$ and thermal $(3.0$ to $100.0 \mu \mathrm{m})$. Solar radiation (that coming from the sun) spans the visible and near infrared wavebands with relatively smaller amounts in the ultraviolet band. Leaves absorb most of the incident radiation in the ultraviolet, visible and thermal portions of the spectrum and reflect or transmit most of the radiation in the near infrared waveband (e.g., Fig. 5-1). For example, Walter-Shea et al. (1987; as cited in Norman \& Arkebauer, 1991) reported values as follows: maize PAR reflectance 0.09, maize PAR transmittance 0.04, maize NIR reflectance 0.38 , maize NIR transmittance 0.45 , soybean PAR reflectance 0.09 , soybean PAR transmittance 0.04 , soybean NIR reflectance 0.42 , soybean NIR transmittance 0.42 . The high absorptivity (often $>0.8$ ) in the visible waveband is due to the presence of plant pigments, notably the chlorophylls but also xanthophylls, carotenoids and anthocyanins (Gates et al., 1965). Chlorophylls absorb strongly 


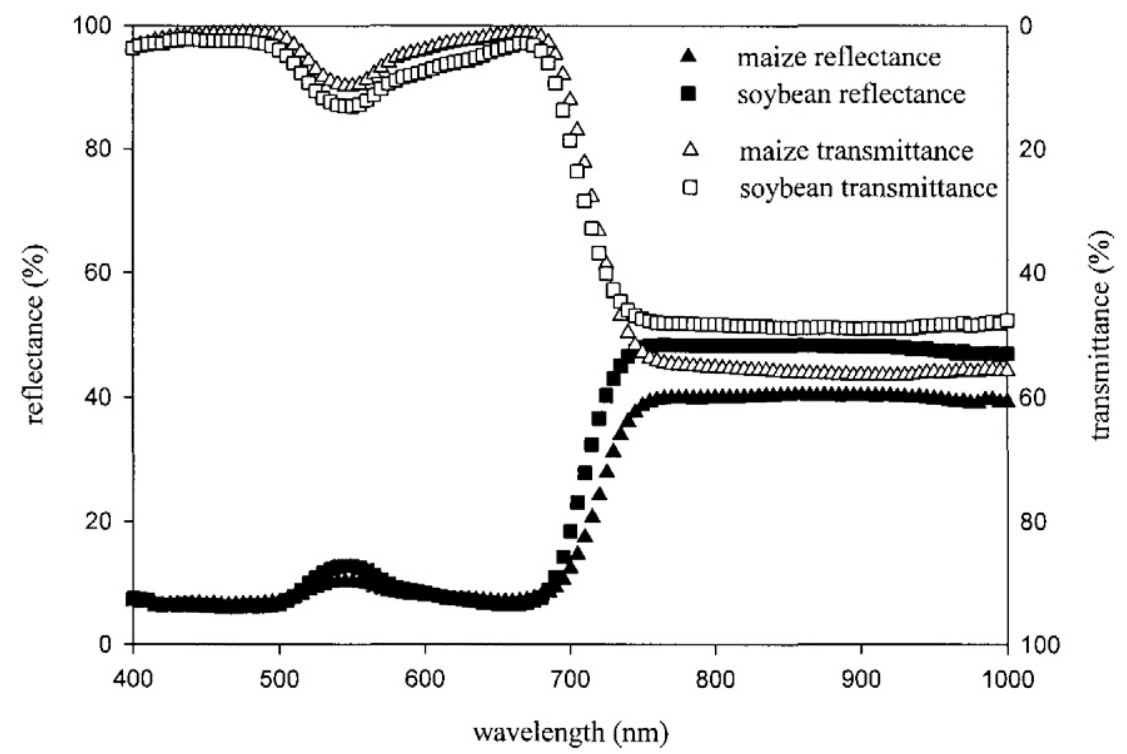

Fig. 5-1. Representative maize and soybean leaf optical properties. Data are means of seven leaves and optical properties were obtained from the abaxial leaf surfaces on Aug. 2, 2002, on plants grown in irrigated plots at the University of Nebraska Agricultural Research and Development Center near Mead, NE, as part of the UNL Carbon Sequestration Project (Data courtesy E.A. Walter-Shea).

in the blue and red regions of the visible waveband; it is their lower absorptivity (hence, higher reflectivity and transmissivity) in the green region that gives leaves their characteristic color. Therefore, leaf optical properties change during leaf development as pigment composition and concentration change. In the near infrared waveband between 0.7 and $1.3 \mu \mathrm{m}$ leaf absorptivity is very low $(<0.1)$. The incident radiation is either reflected or transmitted in approximately equal amounts. These properties are due to the scattering of radiation by refractive index changes between internal air spaces and water-filled cell walls (e.g., Gausman et al., 1969; Knipling, 1970) and to the fact that few leaf constituents absorb radiation over these wavelengths. For near infrared wavelengths greater than 1.3 $\mu \mathrm{m}$, leaf absorptivity increases slightly, due, to a large degree, to energy absorption by water molecules (Knipling, 1970; Woolley, 1971). In the thermal waveband, absorptivities are quite high (often $>0.95$ ). This is in accordance with a principle set forth by Kirchhoff that states the absorptivity equals the emissivity (when they refer to the same wavelength). Leaves at moderate temperatures emit radiation in the thermal waveband. Gates and Tantraporn (1952) and Wong and Blevin (1967) have determined leaf reflectances in the thermal portion of the electromagnetic spectrum for many plant species and found most values to be $<0.05$. For example, in beans (Phaseolus vulgaris L.; cv. Brown Beauty), Wong and Blevin (1967) reported total specular reflectance (at a $10^{\circ}$ incidence angle) to be 0.02 to 0.03 at $5 \mu \mathrm{m}$ and 0.03 to 0.04 at $10 \mu \mathrm{m}$. For the upper surface of sugar- 
cane (Saccharum sp.) leaves, the same authors report reflectances of 0.02 at $5 \mu \mathrm{m}$ and 0.03 at $10 \mu \mathrm{m}$.

Leaf radiative properties have been determined both in the field and in the laboratory. Field determinations using intact leaves are very useful since they avoid possible changes in radiative properties associated with changes in either leaf water content or metabolic activity. In order to measure single leaf properties, a radiometer or spectroradiometer is connected to an integrating sphere. The integrating sphere has ports for leaves, light sources, and detectors. The light source and leaf are usually positioned such that light strikes the leaf in a near-normal incidence angle. Leaf reflectances are determined by placing the detector in a port on the same side of the leaf as the light source; transmittance measurements have the detector located in back of the leaf. The output from the detector is typically divided by the output when the leaf is absent from the integrating sphere (having been replaced by a reflective plug); therefore, the ratio represents the integrated (hemispherical) reflectance or transmittance factor from a specific incidence angle. Quantum sensors have been used as integrating sphere detectors in order to obtain radiative properties in the PAR portion of the spectrum. Bidirectional radiative properties are usually determined in laboratory situations where precise control over source intensity and the direction of incident and detected radiation is possible. More detail on these types of measurements, as well as the determination of canopy radiative properties, can be found in the review of Walter-Shea and Biehl (1990).

Instead of predicting leaf optical properties from leaf physical properties, it is possible, and the subject of much current research, to invert the problem and attempt to infer leaf structure and composition from measurements of leaf optical properties; however, leaves are complex aggregations of diverse materials and thus the spectral responses of whole leaves are made up of many interactions and it is often difficult to discern the composition and concentration of specific substances (e.g, N, chlorophyll) in leaves based on their spectral signatures. Due to the complicated arrangement of structures within plant leaves these investigations frequently rely on empirically-derived relationships or on models of radiative transfer within leaves (e.g., Jacquemoud \& Baret, 1990; Ganapol et al., 1998). Researchers have been especially interested in developing methodologies for remotely-sensed leaf pigment determination due to the obvious association of these pigments and photosynthetic carbon fixation. Reflectances near 550, 700, and $750 \mathrm{~nm}$ have been related to chlorophyll content by Gitelson and Merzlyak $(1996,1997)$ and to carotenoid and anthocyanin content by Gitelson et al. (2001, 2002). Yoder and PettigrewCrosby (1995) estimated $\mathrm{N}$ and chlorophyll contents from near infrared and visible reflectance spectra. Fourty et al. (1996), Kokaly and Clark (1999), and Curran et al. (2001) related reflectance spectra from the ultraviolet through the near infrared to various biochemical compounds including protein, starch, lignin, and cellulose. In addition, Gamon et al. (1990) and Zarco-Tejada et al. $(2000 \mathrm{a}, \mathrm{b})$ related reflectance (at $531 \mathrm{~nm}$ or 680 to $690 \mathrm{~nm}$ ) to chlorophyll fluorescence. This research also has led to the development of reflectance indices for estimating net $\mathrm{CO}_{2}$ uptake and photosynthetic radiation use efficiency (e.g., Gamon et al., 1990, 1997, and others). 


\section{LEAF RADIATION BALANCE}

Although leaf optical properties, in themselves, do not depend strongly on leaf temperature, leaf radiative exchange, i.e., the radiant energy transferred between a leaf and its surroundings, does. Consideration of leaf energy exchange begins with consideration of the leaf radiation balance. The net radiation absorbed by a leaf $\left(R_{\mathrm{n}}\right.$ in $\left.\mathrm{W} \mathrm{m}^{-2}\right)$ can be simply written as:

$R_{\mathrm{n}}=R_{\mathrm{n}}^{\prime}-2 \varepsilon_{\text {leaf }} \sigma T_{\text {leaf }, \mathrm{k}}^{4}$

where $R_{\mathrm{n}}^{\prime}\left(\mathrm{W} \mathrm{m}^{-2}\right)$ is the net incoming, absorbed, radiation from the ultraviolet, visible, near infrared, and thermal wavebands and the second term is the outgoing radiation. The outgoing radiation term arises since the leaf radiates energy similar to a black body and the factor of two comes from energy being emitted from both sides of the leaf. $\varepsilon_{\text {leaf }}$ is known as the leaf emissivity (equivalent to the leaf absorptivity in the thermal waveband) and, as stated above, has typical values of 0.95 to 0.99 . $\sigma$ is the Stefan-Bolzmann constant $\left(5.670 \times 10^{-8} \mathrm{~W} \mathrm{~m}^{-2}{ }^{\circ} \mathrm{K}^{-4}\right)$ and $T_{\text {leaf, } \mathrm{k}}\left({ }^{\circ} \mathrm{K}\right)$ is the leaf temperature. The outgoing term is non-negligible; at $0^{\circ} \mathrm{C}$ it is about $600 \mathrm{~W} \mathrm{~m}^{-2}$ and at $25^{\circ} \mathrm{C}$ it is near $850 \mathrm{~W} \mathrm{~m}^{-2}$. The critical importance of leaf temperature can be seen immediately since the leaf radiates according to the fourth power of its temperature; however, the leaf temperature is influenced by the ultimate partitioning of radiant energy into other processes (e.g., sensible and latent heat fluxes). Thus, solving Eq. [1], i.e., determining the radiant energy exchange between a leaf and its surroundings in a particular situation, depends on knowledge of how this energy partitioning occurs and requires consideration of the leaf energy budget.

\section{LEAF ENERGY BUDGET}

The net radiation absorbed by a leaf $\left(R_{\mathrm{n}}\right)$ must be partitioned to all other energy-using processes occurring at the leaf level. Thus, the leaf energy budget is:

$R_{\mathrm{n}}=H+\lambda E+S+P \approx H+\lambda E$

where $H$ is the sensible heat flux $\left(\mathrm{Wm}^{-2}\right), \lambda E$ is the latent heat flux $\left(\mathrm{Wm}^{-2}\right), S$ is the energy stored by the leaf (caused by changing its temperature), and $P$ is the energy used for photosynthesis. Since the storage and photosynthesis terms are small relative to the sensible and latent heat fluxes, they are usually neglected in the leaf energy budget. Combining Eq. [1] and Eq. [2] gives:

$R_{\mathrm{n}}^{\prime}=H+\lambda E+2 \varepsilon_{\text {leaf }} \sigma T_{\text {leaf }, \mathrm{k}}^{4}$

The leaf energy budget is written in this "practical" manner so that each term can be explicitly measured or calculated; however, as will become apparent, each term in Eq. [3] is dependent on knowledge of the leaf temperature. 


\section{SENSIBLE HEAT FLUX}

The sensible heat flux term $(H)$ accounts for energy transfer between the leaf and its surroundings caused by temperature gradients. These are typically considered as arising from the temperature difference between the leaf and the air around it with the energy transfer due to either forced (wind-driven) or free (no wind) convection. The sensible heat flux term can be written as:

$H=2 \rho c_{\mathrm{p}} g_{\mathrm{b}}\left(T_{\text {leaf }}-T_{\text {air }}\right)$

where $\rho$ is the density of dry air $\left(1.2 \mathrm{~kg} \mathrm{~m}^{-3}\right.$ at $\left.20^{\circ} \mathrm{C}\right), c_{\mathrm{p}}$ is the volumetric heat capacity of dry air at constant pressure $\left(1.2 \mathrm{~kJ} \mathrm{~m}^{-3}{ }^{\circ} \mathrm{C}^{-1}\right), g_{\mathrm{b}}$ is the leaf boundary layer conductance for heat transfer $\left(\mathrm{m} \mathrm{s}^{-1}\right), T_{\text {leaf }}$ is the leaf temperature $\left({ }^{\circ} \mathrm{C}\right)$, and $T_{\text {air }}$ is the air temperature $\left({ }^{\circ} \mathrm{C}\right)$. Again, the factor of two arises since the heat transfer occurs through both the abaxial and adaxial surfaces of the leaf. Once again, in this equation, the importance of leaf temperature becomes explicit, i.e., in order to solve for $H, T_{\text {leaf }}$ (or $\Delta T=T_{\text {leaf }}-T_{\text {air }}$ ) must be known.

\section{LATENT HEAT FLUX}

The latent heat flux term $(\lambda \mathrm{E})$ accounts for energy invested in evaporating water from the leaf. Water is an interesting compound in this regard since it has a very high latent heat of vaporization, $\lambda\left(44.21 \mathrm{~kJ} \mathrm{~mol}^{-1}\right.$ at $\left.20^{\circ} \mathrm{C}\right)$ and thus, as long as leaf stomata are open, a large proportion of the total radiant energy absorbed by the leaf can be partitioned into evaporation. This energy term can be written as:

$\lambda E=\lambda g_{\text {total }}\left[\rho_{\mathrm{w}}^{*}\left(T_{\text {leaf }}\right)-\rho_{\mathrm{w}, \mathrm{air}}\right]$

where $g_{\text {total }}$ is the total leaf conductance for water vapor $\left(\mathrm{cm} \mathrm{s}^{-1}\right.$ or mol m${ }^{-2} \mathrm{~s}^{-1}$, see discussion of units below), $\rho_{\mathrm{w}}^{*}\left(T_{\text {leaf }}\right)$ is the absolute humidity for saturated air at $T_{\text {leaf }}\left(\mathrm{g} \mathrm{m}^{-3}\right)$, and $\rho_{\mathrm{w}, \text { air }}$ is the absolute humidity of the air outside the boundary layer $\left(\mathrm{g} \mathrm{m}^{-3}\right)$. The total leaf conductance, $\mathrm{g}_{\text {total }}$, includes the conductance, in parallel, of both the adaxial and abaxial surfaces of the leaf. The adaxial and abaxial conductances are made up of the stomatal and boundary layer conductances in series. Note that the latent heat flux term, written in this manner, only accounts for water moving from the inside of the leaf to the atmosphere, it does not consider evaporation from a leaf surface. For convenience, Eq. [5] can be written in terms of vapor pressures:

$\lambda E=(\lambda \rho M / P) g_{\text {total }}\left[e^{*}\left(T_{\text {leaf }}\right)-e_{\text {air }}\right]$

where $M$ is the ratio of the molecular weight of water vapor to that of air (0.622), $P$ is the atmospheric pressure $(\mathrm{kPa}), e^{*}\left(T_{\text {leaf }}\right)$ is the saturation vapor pressure at the leaf temperature $(\mathrm{kPa})$, and $e_{\text {air }}$ is the vapor pressure of the air outside the boundary layer $(\mathrm{kPa})$. Since the saturation vapor pressure is a strong function of tem- 
perature the critical importance of the leaf's temperature in determining its energy partitioning is again explicit.

\section{LEAF TEMPERATURE}

The preceding discussion is fine as far as it goes; however, to be of practical use there must be a way to solve resulting set of equations in spite of the rather messy (i.e., non-linear) appearance of leaf temperature in the various energy terms. Given a practical solution, these theoretically sound formulations can be used to address problems related to, for example, leaf photosynthesis, leaf transpiration or leaf radiative exchange since these processes involve a strong dependence on leaf temperature. The energy balance equations can be solved by linearizing them in terms of $\Delta T\left(=T_{\text {leaf }}-T_{\text {air }}\right)$ and solving explicitly for the (unknown) leaf temperature. Note that under well-watered conditions $\Delta T$ is usually negative.

The linearization involves using Taylor series approximations of the $T_{\text {leaf }}$ terms. For the $2 \varepsilon \sigma T_{\text {leaf, }}^{4}$ term, the first two terms of a Taylor series approximation of $T_{\text {leaf, }}^{4}$ expanded around $T_{\text {air, } \mathrm{k}}$ are given as:

$2 \varepsilon \sigma T_{\text {leaf,k }}^{4} \approx 2 \varepsilon \sigma\left(T_{\text {air,k }}^{4}+4 T_{\text {air, }}^{3} \Delta T\right)$

For $T_{\text {air, }}=308^{\circ} \mathrm{K}\left(T_{\text {air }}=35^{\circ} \mathrm{C}\right)$ and $T_{\text {leaf }, \mathrm{k}}=303^{\circ} \mathrm{K}\left(T_{\text {leaf }}=30^{\circ} \mathrm{C}\right)$, this approximation differs from the true value by about $+5 \%$. Similarly, for the latent heat flux term, the first two terms of a Taylor series approximation of $e^{*}\left(T_{\text {leaf }}\right)$ expanded about $e^{*}\left(T_{\text {air }}\right)$ are:

$(\lambda \rho M / P) g_{\text {total }}\left[e^{*}\left(T_{\text {leaf }}\right)-e_{\text {air }}\right] \approx(\lambda \rho M / P) g_{\text {total }}\left[e^{*}\left(T_{\text {air }}\right)+S\left(T_{\text {air }}\right) \Delta T-e_{\text {air }}\right]$

where $S\left(T_{\text {air }}\right)$ is the slope of the saturation vapor pressure versus temperature curve evaluated at $T_{\text {air }}$. Again, for $T_{\text {air }}=35^{\circ} \mathrm{C}$ and $T_{\text {leaf }}=30^{\circ} \mathrm{C}$, this approximation differs from the actual value by about $-4 \%$. Using these approximations, Eq. [3] can be rewritten as:

$$
\begin{aligned}
R_{\mathrm{n}}{ }^{\prime}=(\lambda \rho e / P) g_{\text {total }}\left[e^{*}\left(T_{\text {air }}\right)+S\left(T_{\text {air }}\right) \Delta T-e_{\text {air }}\right] & +2 \rho c_{\mathrm{p}} g_{\mathrm{b}} \Delta T \\
& +2 \varepsilon \sigma T_{\text {air, } \mathrm{k}}^{4}+4 T_{\text {air,k }}^{3} \Delta T
\end{aligned}
$$

thus, the unknown $\Delta T$ is explicitly given as:

$$
\begin{aligned}
\Delta T= & \left\{R_{\mathrm{n}}^{\prime}-(\lambda \rho e / P) g_{\text {total }}\left[e^{*}\left(T_{\text {air }}\right)-e_{\text {air }}\right]-2 \varepsilon \sigma T_{\text {air }, \mathrm{k}}^{4}\right\} / \\
& \left\{(\lambda \rho e / P) g_{\text {total }} S\left(T_{\text {air }}\right)+2 \rho c_{\mathrm{p}} g_{\mathrm{b}}+2 \varepsilon \sigma 4 T_{\text {air }, \mathrm{k}}^{3}\right\}
\end{aligned}
$$

Temperatures of individual leaves (or small portions of leaves) are most conveniently measured with small thermocouples. Copper-constantan thermocouples have reasonable high (voltage) outputs across the temperature range most leaves experience, they are inexpensive, and they can be made using fairly 
small diameter wires that keeps the junction small as well as minimizing thermal conduction along the leads. Small junctions also have the advantage of short time constants that enable quantification of temperature fluctuations. Thermocouples used to measure leaf temperatures should be inserted into the middle of the leaf from the bottom, or attached to the underside of the leaf with surgical tape (e.g., Ehleringer, 1989). Care also must be taken to avoid exposure of thermocouples to direct solar radiation.

Having thus dealt with the nonlinearities in the leaf temperature terms, it is readily apparent that in order to solve Eq. [10], and, in general, in order to understand processes that depend on leaf temperature, we must appreciate the importance of leaf conductance.

\section{LEAF CONDUCTANCE}

Leaf conductances appear explicitly in both the sensible and latent heat flux equations (Eq. [4], [5], and [6]. Moreover, for practical applications, in order to solve the leaf energy budget (Eq. [2] and [3]), we must solve for the leaf temperature (or the leaf to air temperature difference), a solution that implicitly involves knowledge of leaf conductances. Therefore, factors that affect leaf conductances (e.g., light, $\mathrm{CO}_{2}$, plant hormones) also become important when considering, for example, exchange of radiant energy between a leaf and its surroundings.

Amongst plant physiologists leaf conductances are usually expressed in molar units, e.g., stomatal and boundary layer conductances for water vapor are expressed in mol $\mathrm{H}_{2} \mathrm{O} \mathrm{m}^{-2}$ leaf area s${ }^{-1}$; however, historically, micrometeorologists have typically expressed conductances in velocity units (e.g., $\mathrm{cm} \mathrm{s}^{-1}$ ). Conversion between these two ways of expressing conductances is relatively straightforward (e.g., Pearcy et al., 1989):

$\mathrm{g}\left(\mathrm{mol} \mathrm{m}^{-2} \mathrm{~s}^{-1}\right)=\mathrm{g}\left(\mathrm{cm} \mathrm{s}^{-1}\right) 0.446\left(273 / T_{\text {leaf }, \mathrm{k}}\right)(P / 101.3)$

where $P$ is the atmospheric pressure $(\mathrm{kPa})$ and the importance of leaf temperature is, yet again, explicit.

The leaf boundary layer conductance describes the ease with which an entity crosses the layer of still air next to a leaf's surface. The thickness of this layer, and, hence, the accompanying conductance, is a function of both the wind speed near the leaf and the size of the leaf. As the wind speed increases, the conductance increases and as the leaf size increases, the conductance decreases (e.g., Campbell \& Norman, 1998). Boundary layer conductances also depend on leaf anatomy. For example, many plant species growing in water-limited environments have stomata sunken below the leaf surface, thus effectively increasing the thickness of the boundary layer. Also, leaf pubescence (in addition to its importance in determining leaf optical properties) tends to increase leaf boundary layer thickness through its effect on wind speeds near the leaf surface.

The total leaf conductance for water vapor (in Eq. [5] and [6]) represents the ease with which water vapor moves from its source (here, the saturated cell walls within the leaf) to its destination (here considered to be the atmosphere 
around the leaf). As such, as discussed above, it embodies both boundary layer $\left(g_{\mathrm{b}}\right)$ and stomatal $\left(g_{\mathrm{s}}\right)$ components. Additionally, the cuticular conductance is involved; this is the ease with which water moves through the leaf cuticle from epidermal cells to the boundary layer; however, the cuticular conductance is usually much smaller than the other components and it is usually ignored or implicit in $g_{\mathrm{s}}$ due to the (gas exchange) methods whereby $g_{\mathrm{s}}$ is typically quantified. A fourth component of the total conductance is the internal conductance. For water vapor this represents the pathway between the saturated cell walls and the stomatal pore. Again, this component is very small relative to the others and is usually ignored; however, in the case of conductances for $\mathrm{CO}_{2}$ (e.g., conductances associated with photosynthetic $\mathrm{C}$ assimilation), this pathway also would include a portion between the intercellular air spaces and the sites of carboxylation and this additional distance may not be negligible.

Leaf boundary layer conductances are rather straightforward to measure. Usually, a filter paper replica of the leaf is enclosed in a gas exchange cuvette and the resulting transpiration rate is related to $g_{\mathrm{b}}$. Robust relationships have been developed for estimating $g_{\mathrm{b}}$ based on leaf dimensions and wind speeds. Leaf stomatal conductances, however, while not overly difficult to quantify, are not understood well in mechanistic terms. Stomatal conductance is related to a variety of factors including light, $\mathrm{CO}_{2}$ concentration, vapor pressure deficit, and plant hormones (particularly abscisic acid). Given the complex coupling between $g_{\text {s }}$ and environmental and biological parameters, it is not surprising that models of stomatal conductance are, at best, empiricisms based on available evidence. One of the most widely used formulations is the Ball-Berry index:

$g_{\mathrm{s}}=\left(m A n h_{\mathrm{s}} / c_{\mathrm{s}}\right)+b$

where $h_{\mathrm{s}}$ and $c_{\mathrm{s}}$ are the relative humidity and the $\mathrm{CO}_{2}$ concentration within the leaf boundary layer, $\mathrm{An}$ is the net $\mathrm{CO}_{2}$ assimilation rate and $m$ and $b$ are empirically determined coefficients in this linear relationship (Ball et al., 1986). Note that in Eq. [12] $g_{\mathrm{s}}$ refers to stomatal conductance to $\mathrm{CO}_{2}$ whereas in Eq. [9] and [10] the (implicit) $g_{\mathrm{s}}$ refers to water vapor. While the linearity of Eq. [12] is useful, the parameters cannot be easily determined independent of leaf gas exchange data. The strong dependence of $g_{s}$ on light, specifically the amount of absorbed photosynthetically active radiation (i.e., radiation in the visible waveband), highlights once again the intimate association between leaf radiative properties and leaf function.

\section{CONCLUDING REMARKS}

In this brief chapter, a consideration of leaf radiative properties and a desire to apply these to practical problems in agricultural systems has quickly led to a realization of the importance of plant physiological properties, notably leaf conductance. Unfortunately, mechanisms of stomatal responses to environmental conditions are not as yet fully understood. For example, the well-known association of reduced stomatal conductance with increasing vapor pressure deficit is only beginning to be explained (e.g., Matzner \& Comstock, 2001). Therefore, 
advances in physiology will undoubtedly assist in the solution to problems in related fields including micrometeorology.

Globally there is a pressing need to intensify agricultural productivity whilst minimizing environmental consequences. Given the critical agricultural importance of mathematical modeling to understand plant growth, development and productivity, as well as fluxes of energy, water, carbon, etc., there is a real need for cooperation between micrometeorologists, physiologists, plant breeders and others to develop appreciations of each other's work and to take advantage of insights offered by these diverse disciplines. Through interdisciplinary efforts practical solutions to a wide range of interesting problems will be discovered.

\section{REFERENCES}

Ball, J.T., I.E. Woodrow, and J.A. Berry (1986) A model predicting stomatal conductance and its contribution to the control of photosynthesis under different environmental conditions. In J. Biggens (ed.) Progress in photosynthesis research. Vol. 4. Martinus-Nijhoff, The Hague, the Netherlands.

Breece, H.T., and R.A. Holmes. 1971. Bidirectional scattering characteristics of healthy green soybean and corn leaves in vivo. Appl. Optics 10:119-127.

Campbell, G.S., and J.M. Norman. 1998. An introduction to environmental biophysics. 2 nd ed. Springer-Verlag, New York.

Curran, P.J., J.L. Dungan, and D.L. Peterson. 2001. Estimating the foliar biochemical concentration of leaves with reflectance spectroscopy. Remote Sensing Environ. 76:349-359.

Ehleringer, J.R. 1989. Temperature and energy budgets. p. 117-135. In R.W. Pearcy et al. (ed.) Plant physiological ecology. Chapman \& Hall, London.

Fourty, T., F. Baret, S. Jacquemoud, G. Schmuck, and J. Verdebout. 1996. Leaf optical properties with explicit description of its biochemical composition: Direct and inverse problems. Remote Sensing Environ. 56:104-117.

Gamon, J.A., C.B. Field, W. Bilger, O. Björkman, A. Fredeen, and J. PeZuelas. 1990. Remote sensing of the xanthophyll cycle and chlorophyll fluorescence in sunflower leaves and canopies. Oecologia 85:1-7.

Gamon, J.A., L. Serrano, and J.S. Surfus. 1997. The photochemical reflectance index: an optical indicator of photosynthetic radiation use efficiency across species, functional types, and nutrient levels. Oecologia 112:492-501.

Ganapol, B.D., L.F. Johnson, P.D. Hammer, C.A. Hlavka, and D.L. Peterson. 1998. LEAFMOD: A new within-leaf radiative transfer model. Remote Sensing Environ. 63:182-193.

Gates, D.M., H.J. Keegan, J.C. Schleter, and V.R. Weidner. 1965. Spectral properties of plants. Appl. Optics 4:11-20.

Gates, D.M., and W. Tantraporn. 1952. The reflectivity of deciduous trees and herbaceous plants in the infrared to 25 microns. Science (Washingon, DC) 115:613-616.

Gausman, H.W., W.A. Allen, and R. Cardenas. 1969. Reflectance of cotton leaves and their structure. Remote Sensing Environ. 1:19-22.

Gitelson, A.A., and M.N. Merzlyak. 1996. Signature analysis of leaf reflectance spectra: Algorithm development for remote sensing of chlorophyll. J. Plant Physiol. 148:494-500.

Gitelson, A.A., and M.N. Merzlyak. 1997. Remote estimation of chlorophyll content in higher plant leaves. Int. J. Remote Sensing 18:2691-2697.

Gitelson, A.A., M.N. Merzlyak, and O.B. Chivkunova. 2001. Optical properties and nondestructive estimation of anthocyanin content in plant leaves. Photochem. Photobiol. 74:38-45.

Gitelson, A.A., Y. Zur, O.B. Chivkunova, and M.N. Merzlyak. 2002. Assessing carotenoid content in plant leaves with reflectance spectroscopy. Photochem. Photobiol. 75:272-281.

Kokaly, R.F., and R.N. Clark. 1999. Spectroscopic determination of leaf biochemistry using banddepth analysis of absorption features and stepwise multiple linear regression. Remote Sensing Environ. 67:267-287.

Knipling, E.B. 1970. Physical and physiological basis for the reflectance of visible and near-infrared radiation from vegetation. Remote Sensing Environ. 1:155-159. 
Jacquemoud, S., and F. Baret. 1990. PROSPECT: A model of leaf optical properties. Remote Sensing Environ. 34:75-91.

Matzner, S., and J. Comstock. 2001. The temperature dependence of shoot hydraulic resistance: Implications for stomatal behaviour and hydraulic limitation. Plant Cell Environ. 24:1299-1307.

Norman, J.M., and T.J. Arkebauer. 1991. Predicting canopy light-use efficiency from leaf characteristics. p. 125-143. In J.T. Ritchie and J. Hanks (ed.) Modeling plant and soil systems. Agron. Monogr. 31. ASA, Madison, WI.

Pearcy, R.W., E.-D. Schulze, and R. Zimmermann. 1989. Measurement of transpiration and leaf conductance. p. 137-160 In R.W. Pearcyet al. (ed.) Plant physiological ecology. Chapman \& Hall, London.

Walter-Shea, E.A., and L.L. Biehl. 1990. Measuring vegetation spectral properties. Remote Sensing Rev. 5:179-205.

Walter-Shea, E.A., J.M. Norman, and B.L. Blad. 1989. Bidirectional reflectance and transmittance in corn and soybean. Remote Sensing Environ. 29:161-174.

Walter-Shea, E.A., J.M. Norman, B.L. Blad, and B.F. Robinson. 1991. Leaf reflectance and transmittance in soybean and corn. Agron. J. 83:631-636.

Woolley, J.T. 1971. Reflectance and transmittance of light by leaves. Plant Physiol. 47:656-662.

Wong, C.L., and W.R. Blevin. 1967. Infrared reflectances of plant leaves. Aust. J. Biol. Sci. 20:501-508.

Yoder, B.J., and R.E. Pettigrew-Crosby. 1995. Predicting nitrogen and chlorophyll content and concentrations from reflectance spectra (400-2500 nm) at leaf and canopy scales. Remote Sensing Environ. 53:199-211.

Zarco-Tejada, P.J., J.R. Miller, G.H. Mohammed, and T.L. Noland. 2000a. Chlorophyll fluorescence effects on vegetation apparent reflectance: I. Leaf-level measurements and model simulation. Remote Sensing Environ. 74:582-595.

Zarco-Tejada, P.J., J.R. Miller, G.H. Mohammed, T.L. Noland, and P.H. Sampson. 2000b. Chlorophyll fluorescence effects on vegetation apparent reflectance: II. Laboratory and airborne canopy-level measurements with hyperspectral data. Remote Sensing Environ. 74:596-608. 